\title{
Impact of sleep patterns on mood and academic performance of medical students
}

\author{
Ruchi Singh*, Renuka Sharma*, J. C. Suri*, Shobha Das* \\ "Department of Physiology, ${ }^{*}$ Department of Pulmonary, Critical Care \& Sleep Medicine, Vardhman \\ Mahavir Medical College \& Safdarjung Hospital, New Delhi. \\ Indian J Sleep Med 2009; 4.2, 61-67
}

\begin{abstract}
Sleep a vital biological process is essential for physical \& psychological restoration. Owing to their hectic schedules, medical students, in particular, are known to have erratic sleep patterns and suffer from sleep disturbances, fatigue and mood changes. This study was designed to analyze the sleep patterns and to correlate sleep deprivation with incidence of anxiety, depression, daytime sleepiness and performance among 100 students of $1^{\text {st }}$ year MBBS by means of a validated questionnaire. $44 \%$ students reported sleeping $>8 \mathrm{Hrs}$ and only $51 \%$ were regular in their sleep schedule. Females $(32 \%)$ were found to follow a more regular sleep schedule compared to males $(68 \%)$ and reported better performance and lesser level of anxiety and depression in those sleeping for more than $8 \mathrm{hrs}$. Day scholars had a better and a regular schedule compared to hostellers and they also had significantly ( $p=0.034$ ) better performance. This study found that an old saying "early to bed and early to rise makes man healthy, wealthy and wise" holds true. Those following regular schedule, sleeping early and rising early in the morning have better academic performance and lower levels of anxiety and depression. This study highlights the prevalence of disturbed sleep patterns as a significant cause of poor performance and mood disturbances in medical students.
\end{abstract}

Keywords: Sleep deprivation, anxiety, depression, performance.

\section{Introduction}

S leep is a vital biological process essential for physical and psychological restoration and most scientists recommend approximately eight hours of sleep a night to promote efficient performance and thinking. Unfortunately, sleep loss due to voluntary bedtime curtailment has become a hallmark of modern society of which the student community forms an important segment.

\section{Address for correspondence}

\section{Dr J C Suri}

Senior Chest Physician \& Head-Department of Pulmonary, Critical Care \& Sleep Medicine, Vardhman Mahavir Medical College \& Safdariung Hospital, New Delhi. E-mail: jcsuri@rediffmail.com
Insufficient sleep and irregular sleep-wake schedules among adolescents are becoming a major health concern (1). Sleep disturbances are related to decreased quality of life, substance abuse and decreased workplace performance apart from impaired thinking, memory and occurrence of anxiety and depression. Sleep deprivation has also been linked to daytime sleepiness and decreased mental acuity, hence negatively affecting normal learning abilities and skills $(2,3,4)$ Owing to their hectic schedules, medical students, in particular, are known to have erratic sleep patterns and suffer from sleep disturbances, fatigue and mood changes. This study was designed to analyze the sleep patterns of the first year medical students and to detect sleep disturbances, if any and to correlate sleep deprivation with academic performance and incidence of anxiety, depression and daytime sleepiness.

Indian Journal of Sleep Medicine (IJSM), Vol. 4, No. 2, 2009 


\section{Material \& Methods}

A cross-sectional study was conducted among 100 Ist year students of VMMC \& Safdarjung Hospital in the age group of 18-22 years by means of a validated questionnaire. A written, informed consent was obtained from all the subjects. Anthropometric data was recorded and used to calculate B.M.I. A total of 42 questions analyzed the following: Sleep pattern, Sleep latency, Sleep quality, Sleep duration and Sleep disturbance separately for weekdays and holidays (5). Daytime sleepiness was scored using Epsworth Sleepiness Scale (ESS) (6) wherein values of ESS score $>8$ indicated excessive sleepiness (0-8 - normal, 9-12 - mild,13-16moderate and > 16-sever sleepiness). Anxiety, depression and substance abuse among the students was assessed using standardized questions. Out of the eight questions in the anxiety questionnaire, a yes to $\geq 3$ was taken as "probable" anxiety and "imperative" anxiety in case of $\geq 5$ wherein the individual would benefit by counselling. Similarly, in the depression questionnaire consisting of 15 questions, affirmative answers in $\geq 4$ and $\geq 6$ queries were taken as "probable" and "imperative" depression respectively and the latter category would require professional advice. Regarding substance abuse, the students were asked for consumption of caffeine, sleeping pills, alcohol and cigarettes. Performance was calculated based on their overall grades during the academic session.

\section{Statistical methods}

All the data analysis was performed using statistical software SPSS 13. Unpaired t-test and Pearsons correlation were used to determine significance of correlation and testing the differences in the prevalences by characteristics.

\section{Results}

Students enrolled in the present study were divided into various groups on the basis of questionnaire and were analyzed accordingly.

\section{Sleep pattern}

On analyzing the pattern on weekdays and weekends it was observed that most students caught up with their sleep over the weekends (fig-1). Only $44 \%$ of students reported sleep $>8 \mathrm{hrs}$ on weekdays whereas $90 \%$ slept $>8 \mathrm{hrs}$ on weekends which was statistically significant. Bedtime on weekdays and weekends varied to a lesser extent. $62 \%$ of students slept before 12 pm on weekdays which dropped only to $58 \%$ over the weekend.

Figure 1: Total sleep hours on weekend (wetotal) and weekdays (wdtotal)

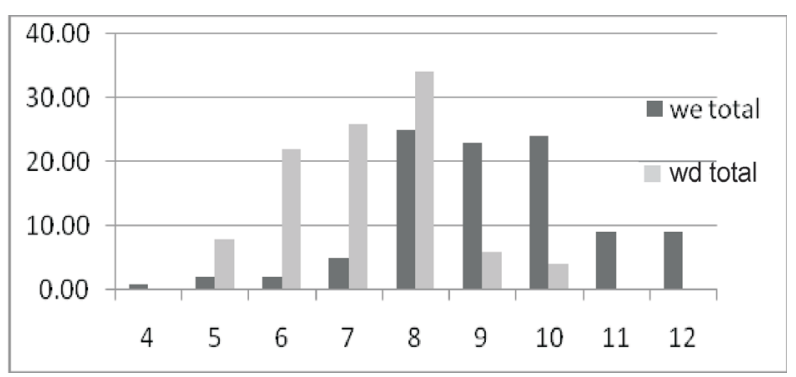

Total hours of sleep and its correlates

On correlating total sleep hours with performance and mood we found a positive correlation with performance $(\mathrm{P}=0.166)$ (Table-1).Though anxiety, depression and excessive sleepiness did not showed any trend on hour to hour comparison but anxiety and depression showed negative correlation with total sleep hours and performance (Table-1).

\section{Time to bed and its correlates}

On comparing different correlates in relation to the student's bedtime, we found that students sleeping earlier had better performance and lower anxiety level than those going to bed late at night. Depression and excessive sleepiness showed mixed trends (Table-2). We also found that time to bed $(\mathrm{P}=0.074)$ is a better determinant of performance than the number of hours of sleep $(\mathrm{P}=0.166)$ (Table 1-2).

Table 1 : Total hours of sleep and its correlates

\begin{tabular}{|c|c|c|c|c|c|c|c|}
\hline Correlates & $\begin{array}{l}5 \mathrm{Hrs} \\
\mathrm{N}=8\end{array}$ & $\begin{array}{l}6 \mathrm{Hrs} \\
\mathrm{N}=22\end{array}$ & $\begin{array}{l}7 \mathrm{Hrs} \\
\mathrm{N}=26\end{array}$ & $\begin{array}{l}8 \mathrm{Hrs} \\
\mathrm{N}=34\end{array}$ & $\begin{array}{l}9 \mathrm{Hrs} \\
\mathrm{N}=6\end{array}$ & $\begin{array}{l}10 \text { Hrs } \\
\mathrm{N}=4\end{array}$ & $\begin{array}{l}\mathrm{P} \\
\text { value }\end{array}$ \\
\hline Performance & $52.18 \pm 10.03$ & $53.75 \pm 8.9$ & $55.38 \pm 9.07$ & $54.26 \pm 2.6$ & $59.58 \pm 5.1$ & $58.75 \pm 11.6$ & 0.166 \\
\hline Anxiety & $1.0 \pm 1.19$ & $2.36 \pm 1.96$ & $1.88 \pm 2.06$ & $1.41 \pm 1.59$ & $1.66 \pm 1.86$ & $1.0 \pm 2.0$ & 0.314 \\
\hline Depression & $2.0 \pm 2.7$ & $4.31 \pm 2.57$ & $3.23 \pm 3.39$ & $3.0 \pm 2.66$ & $2.83 \pm 2.04$ & $3.5 \pm 1.7$ & 0.668 \\
\hline ESS & $8.5 \pm 4.5$ & $8.2 \pm 3.9$ & $9.76 \pm 4.1$ & $10.72 \pm 9.2$ & $7.0 \pm 3.57$ & $10.0 \pm 2.4$ & 0.420 \\
\hline
\end{tabular}


Table 2: Time to Bed and its correlates

\begin{tabular}{|l|l|l|l|l|l|l|l|}
\hline $\begin{array}{l}\text { Bedtime } \\
\text { Variables }\end{array}$ & $\begin{array}{l}10.00 \mathrm{pm} \\
\mathrm{N}=26\end{array}$ & $\begin{array}{l}11.00 \mathrm{pm} \\
\mathrm{N}=26\end{array}$ & $\begin{array}{l}12.00 \mathrm{am} \\
\mathrm{N}=28\end{array}$ & $\begin{array}{l}01.00 \mathrm{am} \\
\mathrm{N}=17\end{array}$ & $02.00 \mathrm{am}$ & $\begin{array}{l}03.00 \mathrm{am} \\
\mathrm{N}=14\end{array}$ & $\begin{array}{l}\mathrm{P} \text { value } \\
\mathrm{N}=5\end{array}$ \\
\hline \hline Performance & $55.25 \pm 6.71$ & $57.69 \pm 8.0$ & $54.19 \pm 9.2$ & $55.0 \pm 10.8$ & $50.35 \pm 9.6$ & $53.5 \pm 8.76$ & 0.074 \\
\hline Anxiety & $1.70 \pm 1.94$ & $1.57 \pm 1.65$ & $1.53 \pm 1.73$ & $1.35 \pm 1.45$ & $2.21 \pm 2.54$ & $3.20 \pm 1.64$ & 0.790 \\
\hline Depression & $3.30 \pm 2.11$ & $3.38 \pm 2.75$ & $2.78 \pm 3.0$ & $3.05 \pm 2.35$ & $3.78 \pm 3.53$ & $4.8 \pm 2.94$ & 0.737 \\
\hline ESS & $9.20 \pm 3.08$ & $8.96 \pm 4.2$ & $8.64 \pm 3.8$ & $9.47 \pm 4.10$ & $12.89 \pm 13.7$ & $8.2 \pm 4.9$ & 0.644 \\
\hline
\end{tabular}

\section{Excessive daytime sleepiness (EDS)}

Excessive daytime sleepiness score (scored by ESS) of $\geq 9$ was found in 52\%. Normal excessive daytime sleepiness score (0-8) of students was seen in only $48 \%$. An extremely high score $>16$ was observed in $6 \%$ of students (Table-3). $67.3 \%$ of males and $32.7 \%$ of females had ESS $>8$.Snoring, depression and anxiety were significantly more in those having excessive sleepiness (Table-4).

Table-3: Epsworth sleepiness score

\begin{tabular}{|l|l|}
\hline Score & Frequency \\
\hline Normal (0-8) & $48 \%$ \\
\hline Mild (9-12) & $36 \%$ \\
\hline Moderate (13-16) & $10 \%$ \\
\hline Severe $(>16)$ & $6 \%$ \\
\hline
\end{tabular}

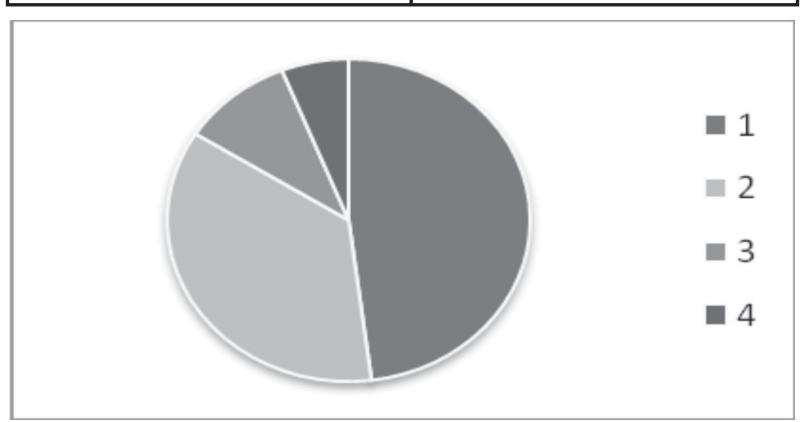

Table 4: Correlates of Excessive Sleepiness (ESS>8)

\begin{tabular}{|l|l|l|l|}
\hline Variables & ESS $>\mathbf{8}$ & ESS $<8$ & P value \\
\hline BMI $(>25)$ & $53.8 \%$ & $46.2 \%$ & 0.827 \\
\hline Snoring & $88.9 \%$ & $11.1 \%$ & $0.02^{*}$ \\
\hline Sleep Deprivation(<8hrs sleep) & $55.4 \%$ & $44.6 \%$ & 0.448 \\
\hline Performance & $54.06 \pm 9.2$ & $55.67 \pm 9.2$ & 0.387 \\
\hline Depression & $40.4 \%$ & $31.3 \%$ & $0.006^{*}$ \\
\hline Anxiety & $29 \%$ & $10.4 \%$ & $0.018^{*}$ \\
\hline
\end{tabular}

\section{Gender differences}

Of the 100 medical students enrolled in the study, there were 32 females and 68 males. On analyzing the two groups, we observed that females followed more regular sleep schedule as compared to males and it was found that they had a significantly different pattern of sleeping earlier as well as waking up before $7 \mathrm{am}$. This was reflected in their performance which was consistently better than the males and also in a much lower incidence of anxiety and depression (Table-5).

Table 5: Gender Differences

\begin{tabular}{|l|l|l|l|}
\hline Variables & $\begin{array}{l}\text { Male } \\
(\mathbf{n}=68)\end{array}$ & $\begin{array}{l}\text { Female } \\
(\mathbf{n}=32)\end{array}$ & Pvalue \\
\hline Sleep before 12 am & $54.4 \%$ & $78.1 \%$ & $0.016^{*}$ \\
\hline Wakeup before 7 am & $58.8 \%$ & $96.9 \%$ & $<0.001^{* *}$ \\
\hline Regular & $44.1 \%$ & $65.6 \%$ & $0.044^{*}$ \\
\hline Total sleep $\geq 8$ hrs & $50 \%$ & $31.3 \%$ & 0.249 \\
\hline Excessive sleepiness (ESS $>12)$ & $16.2 \%$ & $15.5 \%$ & 0.459 \\
\hline Performance & $53.75 \pm 9.66$ & $57.34 \pm 7.87$ & 0.07 \\
\hline Anxiety(score>3) & $19.1 \%$ & $15.6 \%$ & 0.491 \\
\hline Depression (score >4) & $39.6 \%$ & $28.1 \%$ & 0.427 \\
\hline
\end{tabular}

On comparing the two group based on the number of hours of sleep $\{\leq 6 \mathrm{hrs}$ (5-6hrs) and $\geq 8 \mathrm{hrs}$ (8-9hrs) $\}$, we found that performance improved with number of hours of sleep in both the groups while anxiety and depression significantly reduced with increased hours of sleep in females but remained almost same in males.(Table-6)

Table 6: Comparison of different correlates in males and females for those sleeping $\leq 6 \mathrm{hrs}$ and $\geq 8 \mathrm{hrs}$

\begin{tabular}{|l|l|l|l|l|}
\hline \multicolumn{1}{|c|}{ Hrs of sleep } & & $\begin{array}{l}\leq \mathbf{6} \text { hrs } \\
(\mathrm{M}=17, \mathrm{~F}=13)\end{array}$ & $\begin{array}{l}\geq \mathbf{8} \mathbf{h r s} \\
(\mathrm{M}=31, \mathrm{~F}=9)\end{array}$ & P value \\
\hline Variables & $\mathrm{M}$ & $52.35 \pm 9.86$ & $54.19 \pm 9.6$ & 0.533 \\
\hline & $\mathrm{F}$ & $54.61 \pm 8.21$ & $58.05 \pm 6.5$ & 0.310 \\
\hline Anxiety & $\mathrm{M}$ & $1.52 \pm 1.94$ & $1.61 \pm 1.7$ & 0.880 \\
\hline & $\mathrm{F}$ & $2.61 \pm 1.66$ & $0.88 \pm 0.92$ & $0.011^{*}$ \\
\hline Depression & $\mathrm{M}$ & $3.29 \pm 2.9$ & $3.29 \pm 2.6$ & 0.996 \\
\hline & $\mathrm{F}$ & $4.23 \pm 2.48$ & $1.88 \pm 1.7$ & $.006^{*}$ \\
\hline ESS & $\mathrm{M}$ & $8.23 \pm 3.99$ & $10.98 \pm 9.48$ & 0.262 \\
\hline & $\mathrm{F}$ & $8.38 \pm 4.27$ & $7.33 \pm 4.5$ & 0.588 \\
\hline
\end{tabular}

Indian Journal of Sleep Medicine (IJSM), Vol. 4, No. 2, 2009 


\section{Hosteller and Day scholars}

On analyzing the result after grouping the enrolled students as hostellers and day scholars we found that day scholars were more regular in their sleep routines. A significant number of day scholars followed an early to bed and early to rise routine as compared to hostellers who had erratic sleep schedules and usually slept late and also got up later than 7 am. Day scholars recorded a significantly better academic performance as compared to hostellers and also reported significantly less symptoms of excessive daytime sleepiness (Table-7). Though $49 \%$ of day scholars showed signs of depression verses $42 \%$ of hostellers, imperative depression was more frequent in hostellers .Similarly, anxiety was observed to be more in hostellers $(20 \%)$ rather than day scholars (15\%).

Table 7: Comparisons among hostellers and day scholars

\begin{tabular}{|l|l|l|l|}
\hline Variables & $\begin{array}{l}\text { Day Scholar } \\
\mathrm{N}=\mathbf{4 7}\end{array}$ & $\begin{array}{l}\text { Hostellers } \\
\mathrm{N}=53\end{array}$ & $\begin{array}{l}\text { 'P' } \\
\text { Value }\end{array}$ \\
\hline Sleep before 12 a.m. & $85 \%$ & $41.5 \%$ & $<0.001^{* *}$ \\
\hline Wakeup before 7 a.m. & $89.4 \%$ & $54.7 \%$ & $0.004^{*}$ \\
\hline Regular schedule & $66 \%$ & $37.7 \%$ & $<0.001^{* *}$ \\
\hline$\geq 8$ Hrs sleep & $40 \%$ & $47.2 \%$ & 0.436 \\
\hline ESS >12 & $10.6 \%$ & $20.8 \%$ & $.043^{*}$ \\
\hline Depression & $49 \%$ & $42 \%$ & 0.681 \\
\hline Anxiety & $15 \%$ & $20 \%$ & 0.759 \\
\hline Performance & $56.96 \pm 8.12$ & $53.06 \pm 9.85$ & $0.034^{*}$ \\
\hline
\end{tabular}

\section{Exercise, substance abuse, stress and boredom}

Regular exercise was performed by only $13 \%$ of students. $70 \%$ students regularly consumed $\geq 2$ cups of coffee or tea in the evening. 2 students also reported the occasional use of sleeping pills to induce sleep whereas cigarette smoking was seen in only 1 subject while $27 \%$ of students felt they were stressed and $37 \%$ expressed boredom.

\section{Discussion}

Multiple studies in the recent past have documented the high incidence of sleep deprivation in the student community. However, very few studies have been conducted on medical college students who form a very high-risk segment as they have a challenging curriculum to complete during the 4.5years course duration. The incidence of anxiety, depression and substance abuse is known to be high in this segment as a fall out of the intense academic pressure they suffer from. As very little data is available on Indian medical students, this study was conducted among 100 first year students of Vardhman Mahavir Medical College to ascertain the prevalence of sleep deprivation and its correlation to performance and mood disorders.

\section{Sleep patterns}

In the present study, we observed that a large number of students (49\%) were irregular in their sleep habits and their sleep pattern was considerably different during working days as compared to holidays. On analyzing the pattern of sleep on weekdays and weekends among the students, we observed that on weekends (and holidays) most students slept a total of 8 hours or more though there was a tendency to sleep after midnight and till late morning the next day. This pattern is in accordance with the "delayed sleep phase syndrome" which is normally seen in adolescents. DSPS is a circadian-based disorder in which an individual's internal circadian pacemaker is not in synchrony with external or environmental time. Affected adolescents typically experience difficulty in initiating and terminating sleep at a "normal" time ${ }^{(7)}$ and prefer later sleep times and wake times. A shift of about $2 \mathrm{hrs}$ from the normal is seen in these subjects but the sleepstructure of DSPS patients is otherwise normal. Studies have shown the incidence of DSPS is $7 \%$ or more in adolescents $^{(8,9,10)}$. DSPS is characterized by progressive delay in the sleep phase without a decrease in need for sleep (internal factors). The working schedules (external factors) frequently require earlier wake times leading to shorter total sleep time. In our study, we also found sleep deficit in a significant number of students with $56 \%$ of students getting less than $8 \mathrm{hrs}$ of sleep on weekdays. On weekends, a significantly higher number of students (90\%) slept for more than 8 hrs though their time to bed did not differ much on weekdays and weekends. Sleep debt accumulated during the week often leads to prolonged sleep periods or catch-up sleep on weekends causing severe day-to-day irregularities

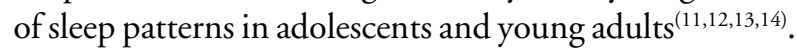

\section{Total hours of sleep and its correlates}

In our study we found students sleeping for more number of hours had better performance (positive correlation) which is in accordance with other studies showing poor performance of students sleeping less on working days $^{(15)}$. The study also showed a negative correlation of anxiety, depression with total hours of sleep and performance, hence the performance of anxious or 
depressed subject was lower. Previous studies have also failed to find whether depression leads to sleepiness or it is the other way round. Kaplan (2007) \& Pilcher et.al. (1996) ${ }^{(16,}$ 17) have shown that mood is more affected by sleep deprivation than either cognitive or motor performance and sleep deprivation has a negative effect on mood. They have also showed a correlation of depression and anxiety with reduced performance ${ }^{(17)}$. Kizilbash $\mathrm{AH}$ et $\mathrm{al}^{(18)}$ have shown that depressive symptoms (without anxiety) have an adverse effect on immediate recall of new information and the amount of acquisition, but not on retrieval or retention. However, symptoms of anxiety (without depression) did not have a significant deleterious effect on any aspect of memory functioning assessed. As suggested by the Yerkes-Dodson 'Law', there is a curvilinear relationship between anxiety and performance, such that a moderate level of anxiety may actually benefit cognitive performance depending on task difficulty ${ }^{(19)}$.

\section{Time to bed and its correlates}

This study also showed that students who slept regularly by $11 \mathrm{pm}$ each day performed consistently better academically. We also found that timing of sleep $(\mathrm{P}=0.074)$ correlated more closely with academic performance than total sleep time $(\mathrm{P}=0.166)$ which is similar to the findings of A.H. Eliasson $^{(11)}$. Those sleeping early exhibited lesser symptoms of anxiety compared to students who had later bed timings. Many studies have suggested that besides the amount (or hours of sleep), the timing is also vital for adequate daytime functioning ${ }^{(20)}$. Since the sleep-wake cycle is in harmony with other inner circadian rhythms, for example, deep body temperature and cellular mitoses, therefore, abrupt shifts of sleep-wake schedules lead to internal dissociation among circadian rhythms, which may imply undesirable effects on mood and may lead to somnolence, attention deficits, concentration difficulties, and performance decrements, which is very common in shift work and rapid travels across multiple time zones ${ }^{(21)}$. In fact, a high prevalence of anxious/ depressive symptoms has been reported in the shift worker population ${ }^{(22)}$. Some studies in undergraduates indicated that irregularities of 2-4 hours in the sleep-wake schedules are associated with higher fatigue, deterioration of mood and performance ${ }^{(23,24)}$. Regarding excessive daytime sleepiness and depression, there was a mixed trend and no specific correlation could be attributed in this study.

\section{Excessive daytime sleepiness (EDS)}

Excessive daytime sleepiness (scored using Epsworth Sleepiness Scale) is strongly linked to sleep deprivation. Various animal and human models have demonstrated that sleep curtailment or fragmented sleep results in excessive daytime sleepiness ${ }^{(25,26)}$. ESS was greater than normal in $52 \%$ with $16 \%$ students recording abnormally high scores (>12). These findings reveal an alarming sleep deficit which could have dangerous consequences especially in students driving themselves to college. Significantly, a high ESS score was associated with an increased incidence of anxiety and depression suggesting lack of sleep as an etiological factor in these disorders. Giannotti et $\mathrm{al}^{(27)}$ also found that Adolescent E-types (preference for evening schedule) showed more irregular life habits and sleep-wake patterns, more sleep problems, less adaptiveness to environmental demands, more daytime sleepiness and vulnerability to injuries and emotional problems. This insufficient sleep may interfere negatively on daytime functions with increasing risk of accidents, injuries, poor attendance and poor academic performance. In our study also we found that high scorers on ESS had poor academic performance. In this study, percentage of snorers was significantly more in those scoring $>8$ on ESS (Table 4) as seen in other earlier studies ${ }^{(28)}$. According to Stradling ${ }^{(29)}$ snoring can be independently associated with EDS.

\section{Gender differences}

On evaluating gender differences, we found that female students adhered to a more regular sleep schedule \& performed better (Table 5). The female students significantly followed an old dictum of "early to bed and early to rise makes person healthy wealthy and wise" similar to the findings of other studies ${ }^{(30,31)}$. Most sleep studies have documented older women complaining of poor sleep, mood disturbances and decreased efficiency ${ }^{(32)}$. Our findings suggest that females in the younger age groups, who are unmarried and not yet burdened with household responsibilities, are able to sleep better and enjoy a better quality of life. On comparing males-females performance $\&$ mood on the basis of total hours of sleep we found that performance of both the group improved as the total hours of sleep increased but its effect on anxiety $\&$ depression were different. Level of anxiety and depression were only slightly affected in males but females showed a significant decrease in the level of anxiety $\&$ depression as their total hours of sleep increased. We also found extreme variation in female's

Indian Journal of Sleep Medicine (IJSM), Vol. 4, No. 2, 2009 
mood suggesting that males were better in coping up with any types of stress. Previous studies ${ }^{(33,34)}$ have also shown increased vulnerability of females to depression. They found that the less effective coping responses involving verbal and self consolatory strategies occur more frequently in females ${ }^{(34)}$.The level of anxiety as well as depression was highest in females as seen in this study which can be explained on the basis that HPA axis is more active in females compared to males due to modulating role of gonadal hormones ${ }^{(35)}$.Halbreich \& Lumley ${ }^{(36)}$ have reported gender differences in neurotransmitter systems traditionally implicated in pathophysiology of depression (noradrenalin \& serotonin). They ${ }^{(36)}$ found a correlation between cortisol levels $\&$ age in younger females but not in males or postmenopausal females, suggesting that hormonal changes during menstrual cycle may contribute to an imbalance in plasma levels of cortisol.

\section{Dayscholars and hostellers}

A comparison of sleep patterns between day-scholars and hostellers also revealed interesting findings. A majority of the hostellers were in the habit of sleeping later than midnight and waking late in the morning. Also, they rarely followed a regular sleep schedule which correlated with a high incidence of daytime sleepiness. On correlation with their academic performance, these students were noted to have a significantly lower performance than the day-scholars. Jean -Louis et al \& Medeiros et al ${ }^{(37,38)}$ have also shown similar findings. The most consistent results were that lower academic grades were associated with less sleep duration ${ }^{38,}$ 39), with later bedtimes / sleep onset ${ }^{(38,39,40)}$ and with later rise times / awakening times ${ }^{(39,40,41)}$. These findings only emphasize the vital role of a regular, uninterrupted and good quality sleep schedule in learning and memory.

\section{Exercise, substance abuse, stress \& boredom}

A survey for substance abuse did not reveal any major finding except for the majority of students reporting regular consumption of tea and coffee similar to many other studies to counteract effect of daytime sleepiness ${ }^{(42,27)}$. Exercise has been well documented to release endorphins, lower stress levels apart from ensuring a good night sleep ${ }^{(43)}$. In our study only $13 \%$ of students regularly exercised which only underlines the lack of physical activity amongst this age group. We feel an urgent need to educate students regarding the benefits of exercise and its vital role in rejuvenating and equipping them to free mental \& physical challenges.

\section{Conclusion}

The study suggests that academic functioning of medical students is deeply associated with sleep and wake patterns. Research on this subject is scanty thus further studies are needed. Based on the findings of this study and the related literature reviewed, we believe that the knowledge about sleep-wake patterns may help us to understand better, its relation with academic failure/success of the students and may be used to improve intervention processes to achieve better academic results.

\section{References}

1. Chung KF; Cheung MM. Sleep-wake patterns and sleep disturbance among Hong Kong Chinese adolescents. SLEEP 2008;31(2):185-194

2. Giannotti F, Cortesi F, Sebastiani T, Ottaviano S: Circadian preference, sleep and daytime behavior in adolescence. $J$ Sleep Res 2002, 11:191-195

3. Sallinen HM, Akila R, Holm A, Luukkonen R, Mikola $H$ : The effects of sleep debt and monotonous work on sleepiness and performance during a 12-h dayshift. J Sleep Res 2004, 13:285-294

4. Wolfson AR, Carskadon MA: Understanding adolescents' sleep patterns and school performance: A critical appraisal. Sleep Med Rev 2003, 7:491-506

5. Hauri P, LindeS. What kind of an insomniac are you? IN: No More Sleepless nights. John Wiley \& Sons Inc. New York $1996 ; 23-42$

6. Johns MW. A new method for measuring daytime sleepiness: the Epworth sleepiness scale. Sleep 1991; 14(6): 540-545

7. Weitzman ED, Czeisler CA, Coleman RM, et al. Delayed sleep phase syndrome. Achronobiological disorder with sleeponset insomnia. Arch Gen Psychiatry. 1981 ;38:737-746

8. Pelayo RP, Thorpy MJ, Glovinsky P. Prevalence of delayed sleep phase syndrome among adolescents. Sleep Res. $1998 ; 17: 391$

9. Regestein QR, Pavlova M. Treatment of delayed sleep phase syndrome. Gen Hosp Psychiatry. 1995; 17:335-345

10. Ando K, Kripke DF, Ancoli-Israel S. Estimated prevalence of delayed and advanced sleep phase syndromes. Sleep Res. 1995;24:509

11. Eliasson AH, Christopher JL, \& Eliasson AH. Early to bed, early to rise! Sleep habits \& academic performance in college students.

12. Carskadon MA, Acebo C. A self-administered rating scale for pubertal development. J. Adol. Health, 1993,14:190-195. 
13. Monk, T. H., Petrie, S. R., Hayes, A. J., Kupfer, D. J. Regularity of daily life in relation to personality, age, gender, sleep quality and circadian rhythms. J.Sleep Res., 1994,3:196205.

14. Violani C, Devoto A, Lucidi F, Pedacchio C, and Rifezzo M. Individual characteristics of subjects able to extend their sleep beyond 10 hours. Sleep Res., 1997, 26: 237.

15. Chung KF; Cheung MM. Sleep-wake patterns and sleep disturbance among Hong Kong Chinese adolescents. Sleep 2008; $31(2): 185-194$.

16. Kaplan J. Sleep Deprivation. In Butkov N, Lee-chiong $\mathrm{T}$ (eds): Fundamentals of sleep technology: Lipincott, Williams \& Wilkins; American Association of sleep Technologists, 2007;p25.

17. Pilcher JJ, Huffcutt Al: Effects of sleep deprivation on performance. A meta analysis. Sleep 19(4):318-326,1996

18. Kizilbash AH, Vanderploeg RD, Curtiss G. The Effects of Depression and Anxiety on Memory Performance (2002). Archives of Clinical Neuropsychology 17 (2002) 57-67.

19. Eysenck $M W(\mathbf{1 9 8 5})$. Anxiety and cognitive-task performance. Personality and Individual Differences, 6,579586

20. Minors DS, Waterhouse JM (1981). Circadian rhythms and the human. Bristol: John Wright \& Sons, Ltd

21. DCSC - Diagnostic Classification Steering Committee (1990). The International Classification of Sleep Disorders. Diagnostic and Coding Manual. American Sleep Disorders Association. Kansa: Allen Press

22. Healy D, Minors DS. and Waterhouse JM. Shiftwork, helplessness and depression. J. Affect Disord. 1993, 29: 17-25.

23. Taub J, Berger R (1973). Performance and mood following variations in the length and timing of sleep. Psychobiology, $10(6), 559-570$.

24. Taub J, Berger R. (1974). The effects of changing phase and duration of sleep. J Exp Psychol Hum Percept Perform, 2, 30-41.

25. Leibowitz SM, Lopes MC, Andersen ML, Kushida CA. Sleep deprivation and sleepiness caused by sleep loss. Sleep Med Clin 2006;(1) : 31-45

26. Suri JC, Sen MK, Singh P, Kumar R, Aggarwal P. Sleep patterns and their impact on lifestyle, anxiety and depression in BPO workers. Indian J sleep Med 2007; 2.2, 64-70.

27. Giannotti F, Cortesi F, Sebastiani T, Ottavivno S. Circadian preference, sleep and daytime behavior in adolescence. J. Sleep Res. (2002) 11, 191-199

28. Suri JC, Sen MK, Adhikari T. Epidemiology of sleep Disorders in the Adult Population of Delhi: A Questionnaire Based Study. Indian J Sleep Med 2008:3.4,128-137

29. Stradling JR, Crosby JH, Payne CD. Self reported snoring and daytime sleepiness in men aged $35-65$ years. Thorax $1991 ; 46: 807-810$
30. Ghanizadeh A, Kianpoor M, Rezaei M, Rezaei H, Moini R, Aghakhani K, Ahmadi J, and Moeini SR . Sleep patterns and habits in high school students in Iran. Ann Gen Psychiatry. $2008 ; 7: 5$

31. Tsai LL, Li SP. Sleep patterns in college students: Gender and grade differences. J Psychosom Res. 2004; $56(2): 23-7$

32. Piccinelli $\mathbf{M}$, Wilkinson $\mathbf{G}$. Gender differences in depression. British Journal of psychiatry. (2000), 177, 486-492.

33. Nolen-Hoeksema S. Sex differences in unipolar depression: evidence and theory. Psychological Bulletin 1987; 101, 259-282.

34. Hänninen $\mathbf{V}$, Aro $\mathrm{H}$. Sex differences in coping \& depression among young adults. Social Science \& Medicine 1996; 43, 1453-1460.

35. Weiss EL, Longhurst JG \& Mazure CM. Childhood sexual abuse as a risk factor for depression in women; psychosocial \& neurobiological correlates. American Journal of Psychiatry 1999; 156, 816-828.

36. Halbreich $\mathbf{U}$, Lumley LA. The multiple interactional biological processes that might lead to depression \& gender differences in its appearances. Journal of Affective disorder $1993 ; 29,159-173$.

37. Jean-Louis G, Gizycki H, Zizi F, Friedman K, Spielman A J, Taylor D, Fullilove R, Taub H. (1996). Psychosocial determinants of sleepiness and performance: consideration of gender differences. Sleep Research, 25, 101

38. Medeiros ALD, Mendes DBF, Lima, PF, Araujo JF. (2001). The relationships between sleep-wake cycle and academic performance in medical students. Biological Rhythm Research, 32 (2), 263-270.

39. Trockel MT, Barnes MD, Egget DL. (2000). Health-related variables and academic performance among first-year college students: implications for sleep and other behaviors. Journal American College Health, 49 (3), 125-131.

40. Smith CS, Reilly C, \& Midkiff K. (1989). Evaluation of three circadian rhythm questionnaires with suggestions for an improved measure of Morningness. Journal of Applied Psychology, 74 (5), 728-738

41. Johns MW, Dudley HAF, \& Masterton JP. (1976). The sleep habits, personality and academic performance of medical students. Medical Education, 10, 158- 162

42. Rosenthal L, Roehrs T, Zwyghuizen-Doorenbos A, Plath D and Roth T. Alerting effects of caffeine after normal and restricted sleep. Neuropsychopharmacology, 1991, 4: 103108.

43. Marques $\mathbf{M}$, Soares MJ, Gomes A, Maia BR, Pereira AT, Valente J, Azevedo MH and Macedo A (2009).P03-228 Sleep patterns and health behaviours in medical students. European Psychiatry, 24, 1, s1227.

Indian Journal of Sleep Medicine (IJSM), Vol. 4, No. 2, 2009 